\title{
Flexible ureterorenoscopy in position or fusion anomaly: Is it feasible?
}

\author{
Rafael Haddad Astolfi ${ }^{1}$, Gustavo Freschl² ${ }^{2}$ Fernando Figueiredo Berti², Nelson Gattas ${ }^{3}$, Wilson Rica Molina Junior ${ }^{4}$, \\ Alex Meller ${ }^{5 *}$ \\ ${ }^{1} \mathrm{MD}$, Urology Resident at Universidade Federal de São Paulo (Unifesp), São Paulo, SP, Brazil \\ ${ }^{2} \mathrm{MD}$, Urology Division, Unifesp, São Paulo, SP, Brazil \\ ${ }^{3} \mathrm{MD}$, Lecturer of Urology, Unifesp, São Paulo, SP, Brazi \\ ${ }^{4}$ Associate Professor, University of Colorado, and Head of the Endourology Department, Denver Health Medical Center, University of Colorado, Denver, CO, USA \\ ${ }^{5} \mathrm{MD}$, Assistant Physician, Urology Division, Unifesp, São Paulo, SP, Brazil
}

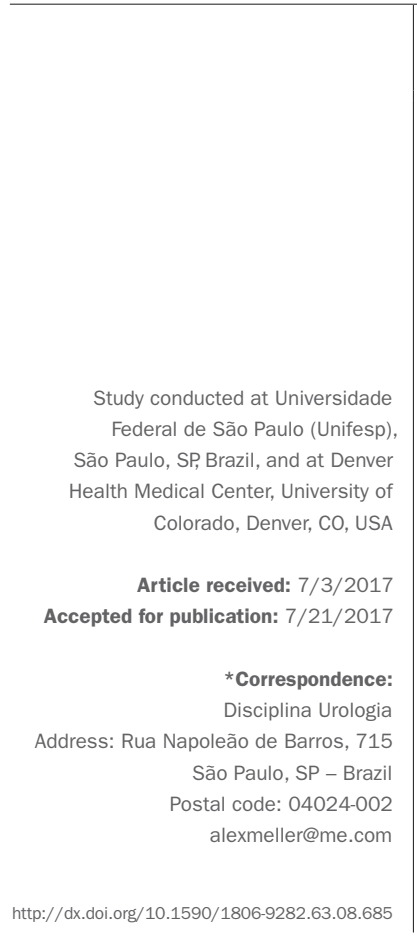

\section{SUMmARY}

Objective: To analyze the results of flexible ureterorenoscopy (F-URS) with holmium laser in the treatment of kidney stones with ectopic and fusion anomalies (horseshoe kidney and rotation anomalies).

Method: We reviewed data from 13 patients with fusion and ectopic renal anomalies that underwent F-URS from April 2011 to April 2017. We analyzed demographic and clinical data (age, gender, BMI, anatomical abnormality, location and dimension of the renal calculi) and perioperative data (method of treatment, stone-free rate, number of days with DJ catheter and perioperative complications). Results: The mean stone size was $12.23+/-5.43 \mathrm{~mm}$ (range $6-22 \mathrm{~mm}$ ), located in the inferior $(58.33 \%)$ and middle $(16.76 \%)$ calyceal units, renal pelvis $(16.67 \%)$ and multiple locations (8.33\%). All 13 patients were treated with Ho-Yag laser, using dusting technique (25\%), fragmentation and extraction of the calculi (58.33\%) and mixed technique (16.67\%). We did not have any severe perioperative complication. After 90 days, nine patients $(75 \%)$ were considered stone free.

Conclusion: Our data suggest that F-URS is a safe and feasible choice for the treatment of kidney stones in patients with renal ectopic and fusion anomalies.

Keywords: urolithiasis, kidney calculi, kidney diseases, fused kidney.

\section{INTRODUCTION}

Nephrolithiasis is an increasingly common condition, affecting $5-15 \%$ of the world's population and mainly individuals at a productive age between the second and sixth decade of life. ${ }^{1}$ In recent years in Brazil, according to Datasus, the number of hospital admissions and costs for the treatment of this condition has increased, with a total expenditure of BRL 29.2 million/year with hospital admissions alone, causing a high impact on public health. ${ }^{2}$

Renal anomalies are relatively rare. Horseshoe kidney (HK) represents the most common fusion anomaly, with an incidence of $0.25 \%$, while the incidence of pelvic kidney varies from $1 / 2,100$ to $1 / 3,000$ and the variance of crossed renal ectopia is $1 / 1,000 .^{3}$ These conditions make it even more challenging to treat urinary lithiasis, with lower success rates in endourologic procedures and increased intraoperative risks due to anatomical differences in renal structure, rotation, and vasculature, ${ }^{4,5}$

Extracorporeal lithotripsy (ESWL) and percutaneous nephrolithotripsy (PCNL) are currently the most common treatment methods for kidneys with fusion or position abnormalities. ${ }^{6-8}$ The choice of flexible ureterorenoscopy with holmium laser - Yag (Ho-Yag) as the first line of treatment for stones $<20 \mathrm{~mm}$ has been increasing due to important technological advances, but only a few studies have reported their results on anomalous kidneys.

\section{Овjective}

To analyze the results of flexible ureterorenoscopy (F-URS) with Ho-Yag laser in the treatment of stones in kidneys with position and fusion anomalies (horseshoe kidneys, pelvic kidneys and crossed renal ectopia), evaluating stone-free 
rates, operative time, difficulty accessing the calyces and complications.

\section{Method}

Data collection

We prospectively collected data from 13 patients with fusion or position abnormalities submitted to the F-URS between April 2011 and April 2017 at the Hospital São Paulo (Federal University of São Paulo - Unifesp, SP, Brazil) and at the Denver Health Medical Center (University of Colorado, CO, USA). Demographic and clinical data (age, gender, BMI, anatomical abnormalities, size and location of the stone), as well as perioperative data (stone treatment method, stone-free index, DJ catheter time and perioperative complications) were collected from the medical records. All patients underwent a control exam within 90 days, either by non contrast-enhanced computed tomography for lithiasis investigation or simple abdominal X-ray. The tomography protocol used the low-dose radioactive modulation technique, with the exception of patients with $\mathrm{BMI}>30 .{ }^{9}$ The abdominal X-ray, in turn, was used for monitoring patients with radiopaque stones and viewed in this examination prior to surgery.

\section{Surgical technique}

The surgical procedures were performed by two endourologists with extensive experience in F-URS (AM, WRM), all under general anesthesia and in a lithotomy position. After performing asepsis and placing sterile fields, cystoscopy was performed with identification of the ureteral meatus looking for abnormalities (duplicity). In all cases, after positioning the guidewire, a semi-rigid retrograde ureteroscopy was performed followed by an attempt to pass an 11/13 Fr or 12/14 ureteral sheath (Boston Scientific). After access to the renal pelvis with the flexible ureteroscope (Storz Flex X2, Oympus URFP5) through the ureteral sheath, a 200 or $273 \mu \mathrm{m}$ laser fiber was used for the treatment of the stone, adjusted according to the stone's location and composition (pulverization, fragmentation and removal or mixed technique). To perform the mobilization or the removal of stones, we used a 1.9 Fr Zero Tip nitinol stone retrieval basket or 1.9 Fr Escape model (Boston Scientific). In all cases, a double J catheter was used postoperatively. Patients in whom residual fragments $<2 \mathrm{~mm}$ were found in the control exams after 90 days were considered as stone free.

\section{RESULTS}

A total of 13 patients (six male and seven female) with anomalous kidney stones (five with rotational defects and eight with horseshoe kidneys) were submitted to the F-URS between 2011 and 2017. A non contrast-enhanced abdominal CT was used to determine the dimensions of the stones, with a mean value of $12.23 \mathrm{~mm}+/-5.43 \mathrm{~mm}$ (ranging from 6 to $22 \mathrm{~mm}$ ), mostly distributed in only one calycinal group (58.33\% in upper calyx, $16.67 \%$ in medium calyx, $16.67 \%$ in pelvis and $8.33 \%$ in multiple calyces). All patients were treated with Ho-Yag laser, with fragmentation and removal of stones in seven cases (58.33\%), pulverization in three cases $(25 \%)$ and mixed technique in two cases (16.67\%).

In relation to perioperative complications, there were no intraoperative complications and only one patient with a rotational defect had a mild complication in the first 24 hours after the procedure (hematuria). There were no patients with Clavien III or IV complications during postoperative monitoring. The DJ catheter was maintained for an average of nine days $+/-3.46$ (ranging from 6 to 14 days). Ninety (90) days after the procedure, nine patients were stone free $(75 \%)$, while residual stones were identified in only three cases (25\%) (Tables 1 and 2).

\section{Discussion}

Renal fusion and positional anomalies are related to an increase in the frequency of kidney stones. ${ }^{10-12}$ Anatomic factors associated with concomitant metabolic disorders contribute to this condition, and make endoscopic treatment difficult. ${ }^{13-15}$

TABLE 1 Preoperative findings.

n (\%) or $\mathbf{n}$

\begin{tabular}{ll}
\hline Age (years) & $46.07+/-13.97$ \\
\hline Sex & $6(46.1 \%)$ \\
Male & $7(53.8 \%)$ \\
Female & $26.06+/-2.4$ \\
\hline BMI & \\
\hline Anatomical anomaly & $5(38.46 \%)$ \\
$\quad$ Rotational defect & $8(61.54 \%)$ \\
$\quad$ Horseshoe kidney & \\
\hline Site of the stone & $7(58.33 \%)$ \\
$\quad$ Lower calyx & $2(16.67 \%)$ \\
$\quad$ Middle calyx & $2(16.67 \%)$ \\
Pelvis & $1(8.33 \%)$ \\
$\quad$ Upper + Middle + Lower calyx & $12.23+/-5.43$ \\
\hline Stone volume (mm) & $924+/-328.01$ \\
\hline Stone density (UH) & $11(84.62 \%)$ \\
\hline Preoperative stent & $2(15.34 \%)$ \\
Yes & \\
No &
\end{tabular}




\section{TABLE 2 Perioperative findings.}

n (\%) or n

\begin{tabular}{ll}
\hline $\begin{array}{l}\text { Treatment method for the stone } \\
\text { Fragmentation }\end{array}$ & $7(58.33 \%)$ \\
Pulverization & $3(25 \%)$ \\
Mixed & $2(16.67 \%)$ \\
\hline Complications within 24h & \\
No & $12(84.61 \%)$ \\
Yes & $1(7.69 \%)$ \\
\hline Time with stent (days) & $9+/-3.46$ \\
\hline Stone-free rate after $30 \mathrm{~d}$ & $9(75 \%)$ \\
Yes & $3(25 \%)$ \\
No &
\end{tabular}

PCNL is the chosen option for the treatment of anomalous kidney stones, especially for stones larger than $20 \mathrm{~mm}$, with stone-free rates between 80 and $90 \%{ }^{16-20}$ The success of the procedure is impaired by features such as renal pelvis and anteriorly positioned calyces, vascular abnormalities and different anatomical relationships with adjacent organs, which increases the risk of perioperative complications and the difficulty of the procedure. ${ }^{6-8} \mathrm{~A}$ routine preoperative abdominal CT scan can reduce the risk of visceral injury in PCNL, especially in pelvic and horseshoe kidneys. ${ }^{20,21}$ Auxiliary methods to aid puncture, such as laparoscopy or ultrasonography, have been described, and present good results. ${ }^{16,17,22}$ However, the potential severity of these lesions, in addition to increasing the inherent cost of these auxiliary procedures, favors the search for more conservative treatments.

ESWL remains an interesting option for anomalous kidneys due to its non-invasive nature, although anatomical variations (high ureter implantation, JUP stenosis, etc.) make it difficult to pass stones in a significant number of patients, and complementary procedures are usually required. ${ }^{1,2}$ The stone-free rates in anomalous kidneys vary in the literature and depend on the dimensions of the stones. Sheir et al. ${ }^{23}$ reported a general success rate of ESWL in anomalous kidneys of $72.2 \%$, with only $46.1 \%$ for stones $>15 \mathrm{~mm} .{ }^{1}$ Tunc et al., ${ }^{24}$ in turn, reported a rate of $92 \%$ for stones $<10 \mathrm{~mm}$, but $34 \%$ for those greater than $30 \mathrm{~mm} .{ }^{3}$ Coupled with lower efficiency of ESWL in eliminating larger stones, Ray et al. ${ }^{13}$ has pointed out that $51 \%$ of their patients needed an additional procedure, but that little improvement occurred after the second session, revealing a limitation in the number of attempts that could be made.

The technological advances in flexible ureteroscopy have allowed its use to be expanded, and it is increas- ingly used in cases of renal anomalies, especially horseshoe kidneys. Its greater deflection capacity (up to $270^{\circ}$ ), coupled with progressively thinner laser fibers and the development of nitinol stone extractors have allowed the access and treatment of stones located in lower calyces or erratically-positioned calyces, leading to stone-free rates ranging from 70 to $88.2 \%$ in up to 1.5 sessions for stones $<30$ $\mathrm{mm}$ in diameter. ${ }^{25-28}$ Techniques such as reallocation of stones from the lower calyx to the middle or upper calyx aid in the success of the procedure by facilitating fragmentation, as well as increasing the useful life of the apparatus by avoiding excessive use of deflection. For cases with residual calculi, ESWL, PCNL or another F-URS session can be performed, but conservative treatment should not be ruled out when possible. In our series of cases, we obtained a stone-free rate of $75 \%$ for stones with a diameter of $12.22 \mathrm{~mm}(+/-5.43 \mathrm{~mm})$, with minimal complication rates (one case of transient hematuria), reinforcing data in the current literature that F-URS is currently a safe and effective procedure for the treatment of stones $<30 \mathrm{~mm}$ in anomalous kidneys.

\section{Conclusion}

Patients with renal position and fusion anomalies are predisposed to the formation of stones and lower success rates in interventional procedures. Although traditionally ESWL and PCNL are the treatments of choice for these patients, advances in F-URS technology have now allowed them to be treated less invasively and with excellent results.

\section{Resumo}

Ureterorrenolitotripsia flexível no tratamento de cálculos em rins anômalos: Qual a viabilidade?

Objetivo: Analisar os resultados da ureterorrenolitotripsia flexível (ULT-F) no tratamento de cálculos em rins com anomalia de posição e de fusão (rins em ferradura e rins com vício de rotação).

Método: Realizamos a coleta prospectiva dos dados de 13 pacientes com anomalias de fusão e de posição submetidos a ULT-F entre abril de 2011 e abril de 2017. Analisaram-se dados clínicos (idade, gênero, IMC, anormalidades anatômicas, dimensão e localização dos cálculos) e perioperatórios (método de tratamento do cálculo, índice de stone free, tempo de cateter DJ e complicações perioperatórias).

Resultados: Nos 13 pacientes, os cálculos mediam em média $12,23 \mathrm{~mm}+/-5,43 \mathrm{~mm}$ (variando de 6 a $22 \mathrm{~mm}$ ), 
em sua maioria distribuídos em apenas um grupo calicinal (58.33\% em grupo calicial inferior, $16.67 \%$ em grupo calicial médio, $16,67 \%$ em pelve e $8,33 \%$ em múltiplos cálices). Todos os pacientes foram tratados com utilização de laser Ho-Yag, com fragmentação e retirada de cálculos em sete casos $(58,33 \%)$, pulverização em três casos $(25 \%)$ e técnica mista em dois casos (16,67\%). Não houve complicações intraoperatórias ou pós-operatórias graves. Após 90 dias, nove pacientes tornaram-se stone free (75\%).

Conclusão: A ULT-F apresenta-se como método seguro e eficaz no tratamento de litíase em rins com anomalia de posição e de fusão.

Palavras-chave: urolitíase, cálculos renais, rim fundido, nefropatias.

\section{References}

1. Lotan Y. Economics and cost of care of stone disease. Adv Chronic Kidney Dis. $2009 ; 16(1): 5-10$.

2. Korkes F, Silva JLS, Heilberg IP. Custo do tratamento hospitalar da litíase urinária para o Sistema Único de Saúde brasileiro. Einstein. 2011; 9(4 Pt 1):518-22.

3. Shapiro E, Bauer SB, Chow JS. Anomalies of the upper urinary tract. In: Wein AJ, ed. Campbell's urology. 10th ed. Philadelphia: W.B. Saunders; 2012. p.3106-43.

4. Bozkurt OF, Tepeler A, Sninsky B, Ozyuvali E, Ziypak T, Atis G, et al. Flexible ureterorenoscopy for the treatment of kidney stone within pelvic ectopic kidney. Urology. 2014; 84(6):1285-9.

5. Grasso M, Beaghler M, Loisides P. The case for primary endoscopic management of upper urinary tract calculi: II. Cost and outcome assessment of 112 primary ureteral calculi. Urology. 1995; 45(3):372-6.

6. Bhatia V, Biyani CS. Calculus disease in duplex system: role of extracorporeal shockwave lithotripsy. Urol Int. 1993; 50(3):164-9.

7. Serrate R, Regué R, Prats J, Rius G. ESWL as the treatment for lithiasis in horseshoe kidney. Eur Urol. 1991; 20(2):122-5.

8. Etemadian M, Maghsoudi R, Abdollahpour V, Amjadi M. Percutaneous nephrolithotomy in horseshoe kidney: our 5-year experience. Urol J. 2013; 10(2):856-60.

9. Fulgham PF, Assimos DG, Pearle MS, Preminger GM. Clinical effectiveness protocols for imaging in the management of ureteral calculous disease: AUA technology assessment. J Urol. 2013; 189(4):1203-13.

10. Gutierrez R. Role of anomalies of kidneys and ureter in causation of surgical conditions. JAMA. 1936; 106(3):183-9.

11. Gupta NP, Mishra S, Seth A, Anand A. Percutaneous nephrolithotomy in abnormal kidneys: single-center experience. Urology. 2009; 73(4):710-4.
12. Yohannes $\mathrm{P}$, Smith $\mathrm{AD}$. The endourological management of complications associated with horseshoe kidney. J Urol. 2002; 168(1):5-8.

13. Ray AA, Ghiculete D, D'A Honey RJ, Pace KT. Shockwave lithotripsy in patients with horseshoe kidney: determinants of success. J Endourol. 2011; 25(3):487-93

14. Esuvaranathan K, Tan EC, Tung KH, Foo KT. Stones in horseshoe kidneys: result of treatment by extracorporeal shock wave lithotripsy and endourology. J Urol. 1991; 146(5):1213-5.

15. Kirkali Z, Esen AA, Mungan MU. Effectiveness of extracorporeal shockwave lithotripsy in the management of stone-bearing horseshoe kidneys. J Endourol. 1996; 10(1):13-5.

16. Mosavi-Bahar SH, Amirzargar MA, Rahnavardi M, Moghaddam SM, Babbolhavaeji H, Amirhasani S. Percutaneous nephrolithotomy in patients with kidney malformations. J Endourol. 2007; 21(5):520-4.

17. Osther PJ, Razvi H, Liatsikos E, Averch T, Crisci A, Garcia JL, et al; Croes PCNL Study Group. Percutaneous nephrolithotomy among patients with renal anomalies: patient characteristics and outcomes; a subgroup analysis of the clinical research office of the endourological society global percutaneous nephrolithotomy study. J Endourol. 2011; 25(10):1627-32.

18. Rana AM, Bhojwani JP. Percutaneous nephrolithotomyin in renal anomalies of fusion, ectopia, rotation, hypoplasia, and pelvicalyceal aberration: uniformity in heterogeneity. J Endourol. 2009; 23(4):609-14.

19. Matlaga BR, Kim SC, Watkins SL, Kuo RL, Munch LC, Lingeman JE. Percutaneous nephrolithotomy for ectopic kidneys: over, around, or through. Urology. 2006; 67(3):513-7.

20. Binbay M, Istanbulluoglu O, Sofikerim M, Beytur A, Skolarikos A, Akman $\mathrm{T}$, et al. Effect of simple malrotation on percutaneous nephrolithotomy: a matched pair multicenter analysis. J Urol. 2011; 185(5):1737-41.

21. Skoog SJ, Reed MD, Gaudier FA Jr, Dunn NP. The posterolateral and the retrorenal colon: implication in percutaneous stone extraction. J Urol. 1985; 134(1):110-2.

22. Holman E, Tóth C. Laparoscopically assisted percutaneous transperitoneal nephrolithotomy in pelvic dystopic kidneys: experience in 15 successful cases. J Laparoendosc Adv Surg Tech A. 1998; 8(6):431-5.

23. Sheir KZ, Madbouly K, Elsobky E, Abdelkhalek M. Extracorporeal shock wave lithotripsy in anomalous kidneys: 11-year experience with two secondgeneration lithotripters. Urology. 2003; 62(1):10-5.

24. Tunc L, Tokgoz H, Tan MO, Kupeli B, Karaoglan U, Bozkirli I. Stones in anomalous kidneys: results of treatment by shock wave lithotripsy in 150 patients. Int J Urol. 2004; 11(10):831-6.

25. Symons SJ, Ramachandran A, Kurien A, Baiysha R, Desai MR. Urolithiasis in the horseshoe kidney: a single-centre experience. BJU Int. 2008; 102(11):1676-80.

26. Weizer AZ, Springhart WP, Ekeruo WO, Matlaga BR, Tan YH, Assimos DG, et al. Ureteroscopic management of renal calculi in anomalous kidneys. Urology. 2005; 65(2):265-9.

27. Molimard B, Al-Qahtani S, Lakmichi A, Sejiny M, Gil-Diez de Medina S, Carpentier X, et al. Flexible ureterorenoscopy with holmium laser in horseshoe kidneys. Urology. 2010; 76(6):1334-7.

28. Atis G, Resorlu B, Gurbuz C, Arikan O, Ozyuvali E, Unsal A, et al. Retrograde intrarenal surgery in patients with horseshoe kidneys. Urolithiasis. 2013; 41(1):79-83. 